\title{
Species Distribution Modeling and Ecological Niche Modeling: Getting the Concepts Right
}

\section{A. Townsend Peterson* \& Jorge Soberón}

Biodiversity Institute, The University of Kansas, Kansas, USA

\begin{abstract}
We provide an overview of conceptual considerations in terminology related to ecological niche modeling and species distribution modeling, two near-synonymous (but not quite), relatively new tools in macroecology and biogeography. We show that a large majority of published studies taking advantage of these tools use terminology inappropriate to the biogeographic and ecological basis on which their application is founded. We suggest that only via rigorous and appropriate terminology will these tools achieve their fullest potential.
\end{abstract}

Key words: Geographic Range, Niche, Species Distributions, Macroecology, Biogeography.

\section{Introduction}

Interest in describing, understanding, and predicting geographic and environmental distributions of species is very old (Wallace 1860; Grinnell 1917). In the last 20 years, methods have been developed to estimate distributional areas on the basis of correlations of known occurrences with environmental variables. Usage of these methodologies has literally exploded in recent years, now with hundreds of papers being published every year (Lobo et al. 2010). Both the fundamental importance of distributional areas as a concept in biogeography and ecology, and myriad applications to which these methods can be applied explain the massively increasing interest in this field (Peterson et al. 2011).

Since the late 1990s, two terminologies have been used to refer to correlative summaries of species' environmental associations and the relationships of those associations to their geographic distributions: "species distribution models" (SDM; Elith \& Leathwick 2009; Franklin 2010) and "ecological niche models" (ENM; Harrison 1997; Peterson et al. 1999); other, more neutral terms have also been used, such as "bioclimatic envelope models" (Araújo \& Peterson 2012). Arguments regarding these terms have been numerous (Peterson 2006; Elith \& Leathwick 2009; Franklin 2010; Sillero 2011; Araújo \& Peterson 2012; Warren 2012) and rather inconclusive. In general, it appears that those who use SDM prefer to avoid overinterpreting the ecological significance of the model, or worry that many dimensions of true ecological niches remain uncharacterized by these methods. The ENM world has emphasized that

*Send correspondence to: A. Townsend Peterson Biodiversity Institute, The University of Kansas, Lawrence, Kansas, 66045, USA

E-mail: town@ku.edu their focus is on a subset of all ecological niche dimensions that is defined in coarse-resolution dimensions that are relatively unlinked to (i.e., not affected by) the population processes of the species in question (Soberón 2007; Soberón \& Nakamura 2009; Soberón 2010). A first in-depth synthesis of concepts in the field was offered recently (Peterson et al. 2011), but has not as-yet seen broad uptake.

The debate between ENM and SDM is far from being merely semantic. It is perfectly feasible to model species' distributions without resorting to a niche definition or even referring to any environmental variables (Jennrich \& Turner 1969; Rapoport 1982; Bahn \& McGill 2007). On the other hand, modeling the processes that produce and shape the area of distribution, transferring causal factors in time or in space, or interpreting biologically the obtained pattern, obviously requires some hypothesis about the ecology of the species, which is clearly a niche-related inquiry.

In this paper, we discuss this dichotomy of terminology. To characterize how these terminologies are used in the field, we searched Web of Science for journal articles that used "species distribution model" or "ecological niche model" under topic or title. Of the 242 papers that resulted, 13 were by one or the other of us, and so were removed from consideration. A further three used the term SDM, but in a very different sense more closely related to environmental chemistry (Lee et al. 1995; Shen et al. 1995; Shen \& Lin 2003); these papers were also removed from analysis.

Because these questions involve subtleties of how terms are used, we focused on the abstract associated with each publication, and the terminology used therein. Of the 226 papers analyzed, 127 used SDM, 51 used ENM, and 50 were 
nonspecific or vague about the concept used or used other terminologies (Table 1). Indeed, two papers used both terms (Colacicco-Mayhugh et al. 2010; Roubicek et al. 2010)! As will be analyzed in greater depth below, no clear divisions existed regarding the uses to which these models were put, such that - in effect - we see simply different terms being used for the same thing.

\section{Conceptual Framework and Real-world Implications}

All of these questions regarding the complexities of ecological niches and geographic distributions require careful and consistent terminology (Peterson et al. 2011). Although other 'vocabularies' have been offered (Godsoe 2010a; Sillero 2011), they have not successfully captured the complexity of the situation: species are distributed in both geographic and environmental dimensions (Colwell \& Rangel 2009), and both geographic and ecological distributions must be captured and linked in any effective terminology. We use the Biotic-Abiotic-Mobility (BAM; Figure 1) framework (Soberón \& Peterson 2005) to contemplate the suites of factors that determine geographic distributions of species, and that have been known and discussed for many decades (Grinnell 1924; Good 1931). This view of species' distributional ecology captures and frames many of the key phenomena for which models of niches and distributions have been used: characterizing niches; interpolating distributional patterns; and anticipating unknown distributional areas, geographic potential of invasive species, and responses to changing environmental conditions.

We contemplate two related spaces. In geographic space G, we can consider several different distributional areas. Areas appropriate in terms of abiotic conditions can be termed $\mathbf{G}_{A}$, or the set of areas that meet the conditions of the fundamental niche $\mathbf{N}_{F}$ of the species. A similar set of constraints applies to biotic conditions, wherein a subset of $\mathbf{G}$ is identified that meets the suite of biotic conditions necessary for the maintenance of populations of the species. Areas that have been accessible to the species over relevant time periods can be termed $\mathbf{M}$, which has been discussed in detail in a previous contribution (Barve et al. 2011). Areas that fulfill both the abiotic and biotic requisites of the species constitute the potential geographic distribution of the species $\mathbf{G}_{p}$, and the intersection of the potential distribution with the accessible areas is termed the occupied distributional area $\mathbf{G}_{O}$; finally, the presently-inaccessible portions of the potential distributional area are termed the invadable area $\mathbf{G}_{I}$.

Besides $\mathbf{G}$, another space is required: in the multivariate space of environmental dimensions, the environments associated with $\mathbf{G}$ are $\eta(\mathrm{G})$, or $\mathbf{E}$. Each of the distributional areas discussed above has a corresponding entity in environmental space: to refer to corresponding elements in environmental space of any distributional area, we use the notation $\mathbf{E}^{\prime}=\eta\left(\mathbf{G}^{\prime}\right)$; its converse operation is $\eta^{-1}\left(\mathbf{E}^{\prime}\right)$, which identifies the geographic location(s) that correspond to a given environmental combination E'.

The fundamental niche $\mathbf{N}_{F}$, however, is not generally fully represented in real-world geography - that is, the fundamental niche is a construct of physiological responses, and may extend to sets of conditions not represented within the study area. The subset of the fundamental niche that is actually represented on relevant landscapes, or the existing fundamental niche, can be defined as $\mathbf{N}_{F} \cap \eta(\mathbf{M})=\mathbf{N}_{F}^{*}$ (Jackson \& Overpeck 2000), and indeed this estimate may be reduced still further if sampling is incomplete across the landscape: if the area sampled is $\mathbf{S}$, then we estimate a yetdifferent set of environments $\widehat{\mathbf{N}}_{F}^{*}=\mathbf{N}_{F} \cap \eta(\mathbf{M} \cap \mathbf{S}) \subseteq \mathbf{N}_{F}^{*}$. This reduction of the fundamental niche is critical in the clarifications offered in this paper, as it basically indicates that any ecological niche that can be estimated on real-world landscapes for real-world species will be only partial, and that these niches can be compared only as conditioned on the $\mathbf{M}$ and $\mathbf{S}$ areas corresponding to each of the species in question(Jiménez-Valverde et al. 2008).

Note that some crucial points have been made here. If 'niche modeling' were genuinely an attempt toestimate fundamental niches, which could then be used to outline $\mathbf{G}_{A}$, then they would not be estimating actual distributional areas, but rather $\mathbf{G}_{p}$, or the potential distribution of the species. Hence, niche model outputs must be processed further (i.e., reduction to the portion of $\mathbf{G}_{A}$ that is within $\mathbf{M}$ ) if an actual (occupied) distributional area is to be identified. Second, on the environmental side, these approaches at best can characterize $\mathbf{N}_{F}^{*}$, which is the fundamental niche conditioned on the associated $\mathbf{M}$ and $\mathbf{S}$ - these niche estimates are not comparable without explicit reference to $\mathbf{M}$ and $\mathbf{S}$. These two points have massive implications for what researchers are 'doing' with these techniques at the moment.

Table 1. Summary of uses to which different studies have put analyses under the rubrics of 'ecological niche modeling' and 'species distribution modeling.

\begin{tabular}{lccc}
\hline & Ecological niche modeling & Species distribution modeling & Total \\
\hline Climate change projections & 12 & 35 & 47 \\
Distributional prediction & 19 & 62 & 81 \\
Species invasions projections & 7 & 22 & 29 \\
Niche characterization & 2 & 3 & 5 \\
Paleodistributional predictions & 11 & 4 & 15 \\
Total & 51 & 126 & 177 \\
\hline
\end{tabular}




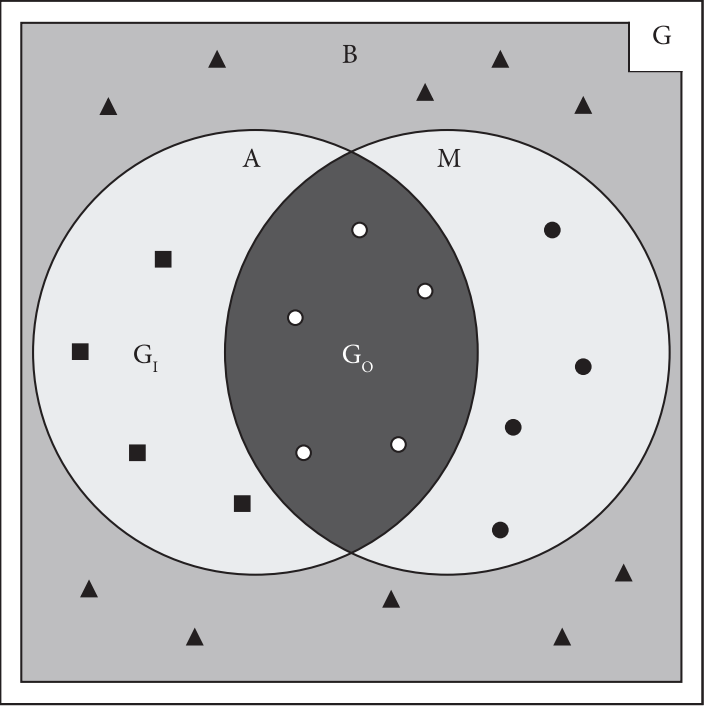

Figure 1. A BAM diagram configuration that may be most relevant to broad geographic questions about species' geographic distributions. That is, as argued by Soberón (2007), biotic considerations may frequently be diffuse and non-limiting, or may be manifested at spatial resolutions so fine as to be nestled within the coarse-resolution phenomena that are the focus of most ecological niche modeling and species distribution modeling studies. The circle $\mathbf{A}$ represents the parts of the world that contain the abiotic conditions required for a species' survival and growth. The circle $\mathbf{M}$ represents the region that has been accessible to the species over a relevant period of time. The intersection of these two regions is the occupied area $\mathbf{G}_{0}$; $\mathbf{G}_{I}$ holds the correct suite of environmental conditions, but has not been explored by the species; open circles represent presence data; closed circles indicate absences due to incorrect environment; closed squares indicate absences due to lack of dispersal capacity; and triangles indicate absences owing to both incorrect conditions and limited dispersal. Note that absences can also occur within $\mathbf{G}_{O}$ as well. From Saupe et al. (2012).

\section{What is the Target of Modeling?}

Some early thinking approaches to understanding species' distributions were developed in exclusively spatial dimensions, while others were developed in exclusively environmental dimensions (Hutchinson 1957; Brown et al. 1996). Indeed, space-only approaches to mapping species' distributions continue strong in the field of spatial epidemiology, in which, in many studies, disease distributions are estimated and characterized only in dimensions of space, and frequently with no reference to environmental conditions (Pfeiffer et al. 2008; Lai et al. 2009). The environment-only tradition continues also, but quietly, hidden as an unstated assumption of many studies under the rubric of ecological niche modeling or species distribution modeling (see "When are Species' Distributions Modeled Correctly?" below).

In essentially all modern applications of these techniques, however, the process involves at least two transitions between spaces. That is, known occurrences, $\mathbf{G}_{+}$, are distributed across geographic space. The modeling process involves comparing environments associated with occurrences $\eta\left(\mathbf{G}_{+}\right)$ with those associated with some set of data representing non-occurrences. Hence, the model is developed in environmental space, and the target of modeling is some subset of $\mathbf{E}$, and not an area of $\mathbf{G}$. However, in most modern studies, the model is then used to classify areas of geographic space as to whether they present conditions that are in some sense similar to $\eta\left(\mathbf{G}_{+}\right)$or not - this assessment of similarity establishes whether a site is considered as suitable or not for the species. Hence, in this process, the initial steps are carried out in geographic space, the model is fitted in environmental space, and model outputs are generally visualized in geographic space.

\section{Species Distribution Modeling or Ecological Niche Modeling?}

These seemingly different terms refer to what is in effect the same set of analyses, as can be appreciated from the Introduction and Table 1. In the strictest sense, one could assert that the target of model fitting is inevitably some entity in environmental space, which is the realm of niches, and not distributions. In that sense, essentially all modern applications of these techniques should be considered models of ecological niches, which then may be used for a variety of purposes - understanding actual or potential distributional areas, characterizing ecological niches, etc.

Most SDM/ENM studies use something chosen from basically the same set of mathematical algorithms, similar sorts of occurrence data, and the same sets of environmental variables, and both can produce outputs in the form of maps; indeed, papers from the two are published in the same journals. As a consequence, many people fail to perceive that the questions posed in modeling distributions (in a narrow sense) and modeling environments are very different. That is, in SDM and ENM, researchers attempt to calculate very different objects, and a distinction between these two concepts would focus on how geographic areas of interest are identified and characterized. To model a species' distribution, in view of the conceptual framework offered above, one must estimate $\mathbf{N}_{F}$, which in turn allows identification of some hypothesis of $\mathbf{G}_{A}$. Separately, one must assess $\mathbf{M}$, which is often not a simple enterprise (Barve et al. 2011). Then, the species' actual (occupied) distributional area is $\mathbf{G}_{O}=\mathbf{G}_{A} \cap \mathbf{M}$. So, in sum, genuine "species distribution modeling" must include steps of niche estimation and steps of assessment of dispersal ability or colonization potential (e.g., van Loon et al. 2011). The following section ("When are Species' Distributions Modeled Correctly?") assesses how frequently studies in this field take all of these necessary steps.

Certainly, though, some combinations of these terms and particular applications are not correct. SDM can focus only on the actual distribution - any other use, such as estimating invasive potential or assessing effects of environmental change on species' distributional potential, requires an 
explicit estimate of $\mathbf{N}_{F}$, and as such must fall under the rubric of ENM. Indeed, of SDM studies, almost half focus on distributional prediction (62 of 126 studies, $49.2 \%$ ); however, $27.8 \%$ focus on climate change projections, $17.5 \%$ focus on projections of distributional potential of invasive species, $3.2 \%$ make projections of paleodistributional patterns, and $2.4 \%$ set out explicitly to characterize the species' ecological niche (!), as is detailed in Table 1 . These $50.8 \%$ of species distribution models thus use inconsistent and illogical terminology, and should rather be termed ENMs.

\section{When are Species' Distributions Modeled Correctly?}

For those studies that set out to characterize species' geographic distributions (19 ENMs and 62 SDMs), a further question is whether concepts are managed correctly. As detailed above (see "Conceptual Framework and Real-world Implications"), the term 'distribution' has many versions, such that any study purporting to estimate distributions must either (1) restrict model calibration to accessible areas $(=\mathbf{M})$, for which assumptions regarding access must be stated explicitly (Barve et al. 2011), thereby estimating $\mathbf{G}_{O}$ directly; (2) trim modeled hypotheses of $\mathbf{G}_{A}$ to match hypotheses of accessibility and thereby estimate $\mathbf{G}_{O}$; (3) incorporate dispersal into analyses explicitly (Robinson et al. 2011; Boulangeat et al. 2012), again estimating $\mathbf{G}_{O}$ directly; (4) use true absences as a contrast to presences in model calibration and expect that restrictive factors will be captured indirectly as a consequence (Ward et al. 2009), or (5) state explicitly that the model outputs are potential distributions and not actual distributional area predictions. Hence, we reviewed the methods section of each of the studies that had distributional prediction as a main objective to assess the degree to which they handled the distinction between actual and potential distributions appropriately.

Of the 81 studies, we discarded 16 because they were not empirical in nature and thereby did not confront these issues directly, and we discarded a further 5 studies because access to the full published version was overly difficult, even under the University of Kansas' rather expensive electronic journal access expenditures (such difficult-to-access journals will have to survive without our citations!); hence, we analyzed a total of 60 papers. Of these 60 papers, 32 made no indication of any species-specific considerations as to access to areas or any of the criteria listed above; although some of these analyses were cast on such small spatial extents that access was probably assumed (but not stated explicitly), a large proportion of these studies simply did not state any explicit thought to these considerations. A significant $2 \times 2$ interaction existed between whether the authors used the SDM versus ENM terminology, and whether accounting was made for the difference between potential and actual distributions, with those using SDM tending towards lack of documentation more frequently than expected at random $\left(\chi^{2}=10.01, \mathrm{df}=1, P<0.002\right)$.

\section{When are Ecological Niches Modeled and Compared Correctly?}

Only five studies focused explicitly on estimating and comparing ecological niches out of the sample that we considered (Table 1); of these studies, three used SDM terminology and two used ENM terminology, so no strong tendency was noted. Considering the need for niche estimates and their comparisons to be conditioned on species-specific estimates of $\mathbf{M}$ (Barve et al. 2011) as discussed above, we assessed each of the five studies as to whether some species-specific area was included in the comparisons.

One paper (Rodder \& Engler 2011) discussed metrics of niche overlap and cited key concepts and references, but did not enter into detail about means of comparison and manipulation that they recommended (Warren et al. 2008). Of the remaining four papers, three appropriately considered species-specific areas in their niche comparisons (Godsoe 2010b; Nakazato et al. 2010; Schulte et al. 2012), but one relied on direct comparisons of estimates of niches and distributions, which is quite perilous and likely misleading (Hoisington-Lopez et al. 2012).

\section{Conclusions}

We reviewed a representative swath of the recent scientific literature, pondering the degree to which these publications use different terminologies, and the degree to which they hold logical and conceptual inconsistencies. We found considerable cause for concern, such that half of the studies using the terminology "species distribution modeling" nonetheless take advantage of the models for uses related to ecological niches. What is more, about two-thirds of SDM-termed studies and a non-zero number of ENM-termed studies that focus on estimating geographic distributions fail to make appropriate distinctions between actual and potential distributional areas. Finally, one-quarter of a very small sample of studies comparing estimates of ecological niches of species used inappropriate methodologies as well. In sum, an impressive proportion of studies in this emerging field of whole-range species-level ecological biogeography carry logical and conceptual inconsistencies that compromise the rigor of their conclusions.

It is certainly tempting to pass these concerns off as 'just words' (see, e.g., Godsoe 2010a). We argue that this field is compromised by this lack of rigor, however: not only is its credibility in the broader scientific community reduced (Hampe 2004; Sinclair et al. 2010), but also many confusions and inappropriate conclusions have been reached for lack of conceptual rigor (Peterson 2011; Soberón \& Peterson 2011; Araújo \& Peterson 2012). "ENM" should be used only when focus is on estimation of $\mathbf{N}_{F}$ or $\mathbf{G}_{A}$ or any potential distribution under changed conditions and circumstances, but care must be taken to distinguish these quantities from their 'existing' or 'realized' manifestations; on the other hand, 
"SDM" must include steps to transform areas estimated from potential to actual, so as to reconstruct distributions accurately. If this field is to mature into an important and unique element in the ecological and biogeographic toolkit, greater conceptual rigor will be required.

\section{Acknowledgements}

Our work was supported by a grant from Microsoft Research (\#47780).

\section{References}

Araújo MB \& Peterson AT, 2012. Uses and misuses of bioclimatic envelope modelling. Ecology, 93:1527-1539. http://dx.doi. org/10.1890/11-1930.1

Bahn V \& McGill BJ, 2007. Can niche-based distribution models outperform spatial interpolation? Global Ecology and Biogeography, 16:733-742. http://dx.doi. org/10.1111/j.1466-8238.2007.00331.x

Barve $\mathrm{N}$ et al., 2011. The crucial role of the accessible area in ecological niche modeling and species distribution modeling. Ecological Modelling, 222:1810-1819. http:// dx.doi.org/10.1016/j.ecolmodel.2011.02.011

Boulangeat I, Gravel D \& Thuiller W, 2012. Accounting for dispersal and biotic interactions to disentangle the drivers of species distributions and their abundances. Ecology Letters, 15:584-593. http://dx.doi. org/10.1111/j.1461-0248.2012.01772.x

Brown JH, Stevens GC \& Kaufman DM, 1996. The geographic range: Size, shape, boundaries, and internal structure. Annual Review of Ecology and Systematics, 27:597-623. http://dx.doi. org/10.1146/annurev.ecolsys.27.1.597

Colacicco-Mayhugh MG, Masuoka PM \& Grieco JP, 2010. Ecological niche model of Phlebotomus alexandri and P. papatasi (Diptera: Psychodidae) in the Middle East. International Journal of Health Geographics, 9. http://dx.doi. org/10.1186/1476-072X-9-2

Colwell RK \& Rangel TF, 2009. Hutchinson's duality: The once and future niche. Proceedings of the National Academy of Sciences USA, 106:19644-19650. http://dx.doi.org/10.1073/ pnas.0901650106

Elith J \& Leathwick J, 2009. Species distribution models: Ecological explanation and prediction across space and time. Annual Review of Ecology, Evolution, and Systematics, 40:677-697. http://dx.doi.org/10.1146/annurev. ecolsys.110308.120159

Franklin J, 2010. Mapping Species Distributions: Spatial Inference and Prediction. Cambridge: Cambridge University Press. http://dx.doi.org/10.1017/CBO9780511810602

Godsoe W, 2010a. I can't define the niche but I know it when I see it: A formal link between statistical theory and the ecological niche. Oikos, 119:53-60. http://dx.doi. org/10.1111/j.1600-0706.2009.17630.x

Godsoe W, 2010b. Regional variation exaggerates ecological divergence in niche models. Systematic Biology, 59:298-306. http://dx.doi.org/10.1093/sysbio/syq005
Good RD, 1931. A theory of plant geography. New Phytologist, 30:149-171. http://dx.doi. org/10.1111/j.1469-8137.1931.tb07414.x

Grinnell J, 1917. Field tests of theories concerning distributional control. American Naturalist, 51:115-128. http://dx.doi org/10.1086/279591

Grinnell J, 1924. Geography and evolution. Ecology, 5:225-229. http://dx.doi.org/10.2307/1929447

Hampe A, 2004. Bioclimate envelope models: What they detect and what they hide. Global Ecology and Biogeography, 13:469471. http://dx.doi.org/10.1111/j.1466-822X.2004.00090.x

Harrison S, 1997. How natural habitat patchiness affects the distribution of diversity in Californian serpentine chaparral. Ecology, 78:1898-1906. http://dx.doi. org/10.1890/0012-9658(1997)078[1898:HNHPAT]2.0.CO;2

Hoisington-Lopez JL, Waits LP \& Sullivan J, 2012. Species limits and integrated taxonomy of the Idaho ground squirrel (Urocitellus brunneus): Genetic and ecological differentiation. Journal of Mammalogy, 93:589-604. http:// dx.doi.org/10.1644/11-MAMM-A-021.1

Hutchinson GE, 1957. Concluding remarks. Cold Spring Harbor Symposia on Quantitative Biology, 22:415-427. http://dx.doi org/10.1101/SQB.1957.022.01.039

Jackson ST \& Overpeck JT, 2000. Responses of plant populations and communities to environmental changes of the Late Quaternary. Paleobiology, 26(Supplement):194-220. http:// dx.doi.org/10.1666/0094-8373(2000)26[194:ROPPAC] 2.0.CO;2

Jennrich RI \& Turner FB, 1969. Measurment of non-circular home range. Journal of Theoretical Biology, 22:227-237. http://dx.doi.org/10.1016/0022-5193(69)90002-2

Jiménez-Valverde A, Lobo JM \& Hortal J, 2008. Not as good as they seem: The importance of concepts in species distribution modelling. Diversity and Distributions, 14:885-890. http:// dx.doi.org/10.1111/j.1472-4642.2008.00496.x

Lai P-C, So F-M \& Chan K-W, 2009. Spatial Epidemiological Approaches in Disease Mapping and Analysis. Boca Raton: CRC Press.

Lee KW, Cho SH \& Park SW, 1995. Studies on the treatment of waste-water bearing cyanide and heavy-metals by micelle enhanced ultrafiltration technique. Journal of Environmental Science and Health A, 30:467-484. http:// dx.doi.org/10.1080/10934529509376212

Lobo JM, Jiménez-Valverde A \& Hortal J, 2010. The uncertain nature of absences and their importance in species distribution modelling. Ecography, 33:103-114. http:// dx.doi.org/10.1111/j.1600-0587.2009.06039.x

Nakazato T, Warren DL \& Moyle LC, 2010. Ecological and geographic models of species divergence in wild tomatoes. American Journal of Botany, 97:680-693. http://dx.doi org/10.3732/ajb.0900216

Peterson AT, 2006. Uses and requirements of ecological niche models and related distributional models. Biodiversity Informatics, 3:59-72.

Peterson AT, 2011. Ecological niche conservatism A time-structured review of evidence. Journal of Biogeography, 38:817-827. http://dx.doi. org/10.1111/j.1365-2699.2010.02456.x 
Peterson AT et al., 2011. Ecological Niches and Geographic Distributions. Princeton: Princeton University Press.

Peterson AT, Soberón J \& Sánchez-Cordero V, 1999. Conservatism of ecological niches in evolutionary time. Science, 285:1265-1267. http://dx.doi.org/10.1126/ science.285.5431.1265

Pfeiffer D et al., 2008. Spatial Analysis in Epidemiology. Oxford: Oxford University Press. http://dx.doi.org/10.1093/acprof :oso/9780198509882.001.0001

Rapoport EH, 1982. Aerography: Geographical Strategies of Species. Oxford: Pergamon Press.

Robinson LM et al., 2011. Pushing the limits in marine species distribution modelling: lessons from the land present challenges and opportunities. Global Ecology and Biogeography, 20:789-802. http://dx.doi. org/10.1111/j.1466-8238.2010.00636.x

Rodder D \& Engler JO, 2011. Quantitative metrics of overlaps in Grinnellian niches: advances and possible drawbacks. Global Ecology and Biogeography, 20:915-927. http://dx.doi. org/10.1111/j.1466-8238.2011.00659.x

Roubicek AJ et al., 2010. Does the choice of climate baseline matter in ecological niche modelling? Ecological Modelling, 221:2280-2286. http://dx.doi.org/10.1016/j. ecolmodel.2010.06.021

Saupe E et al., 2012. Variation in niche and distribution model performance: The need for a priori assessment of key causal factors. Ecological Modelling, 237-238:11-22. http://dx.doi. org/10.1016/j.ecolmodel.2012.04.001

Schulte U et al., 2012. Cryptic niche conservatism among evolutionary lineages of an invasive lizard. Global Ecology and Biogeography, 21:198-211. http://dx.doi. org/10.1111/j.1466-8238.2011.00665.X

Shen YS, Ku Y \& Lee KC, 1995. The effect of light absorbency on the decomposition of chlorophenols by ultraviolet-radition and $\mathrm{UV} / \mathrm{H}_{2} \mathrm{O}_{2}$ processes. Water Research, 29:907-914. http:// dx.doi.org/10.1016/0043-1354(94)00198-G

Shen YS \& Lin CC, 2003. The effect of $\mathrm{pH}$ on the decomposition of hydrophenols in aqueous solutions by ultraviolet direct photolysis and the ultraviolet-hydrogen peroxide process. Water Environment Research, 75:54-60. http://dx.doi. org/10.2175/106143003X140827
Sillero N, 2011. What does ecological modelling model? A proposed classification of ecological niche models based on their underlying methods. Ecological Modelling, 222:13431346. http://dx.doi.org/10.1016/j.ecolmodel.2011.01.018

Sinclair SJ, White MD \& Newell GR, 2010. How useful are species distribution models for managing biodiversity under future climates? Ecology and Society, 15:8.

Soberón J, 2007. Grinnellian and Eltonian niches and geographic distributions of species. Ecology Letters, 10:1115-1123. http:// dx.doi.org/10.1111/j.1461-0248.2007.01107.x

Soberón J, 2010. Niche and area of distribution modeling: a population ecology perspective. Ecography, 33:159-167. http://dx.doi.org/10.1111/j.1600-0587.2009.06074.x

Soberón J \& Nakamura M, 2009. Niches and distributional areas: Concepts, methods, and assumptions. Proceedings of the National Academy of Sciences USA, 106:19644-19650. http://dx.doi.org/10.1073/pnas.0901637106

Soberón J \& Peterson AT, 2005. Interpretation of models of fundamental ecological niches and species' distributional areas. Biodiversity Informatics, 2:1-10.

Soberón J \& Peterson AT, 2011. Ecological niche shifts and environmental space anisotropy: A cautionary note. Revista Mexicana de Biodiversidad, 82:1348-1353.

Van Loon AH et al., 2011. Linking habitat suitability and seed dispersal models in order to analyse the effectiveness of hydrological fen restoration strategies. Biological Conservation, 144:1025-1035. http://dx.doi.org/10.1016/j. biocon.2010.12.021

Wallace AR, 1860. On the zoological geography of the Malay Archipelago. Proceedings of the Linnean Society of London, 4:172-184. http://dx.doi. org/10.1111/j.1096-3642.1860.tb00090.x

Ward G et al., 2009. Presence-only data and the EM algorithm. Biometrics, 65:554-563. http://dx.doi. org/10.1111/j.1541-0420.2008.01116.x

Warren DL, 2012. In defense of 'niche modeling. Trends in Ecology \& Evolution, 27:497-500. http://dx.doi.org/10.1016/j. tree.2012.03.010

Warren DL, Glor RE \& Turelli M, 2008. Environmental niche equivalency versus conservatism: quantitative approaches to niche evolution. Evolution, 62:2868-2883. http://dx.doi. org/10.1111/j.1558-5646.2008.00482.x 